department. For instance, a message about your library's online collection of textbooks could be directed to those nurses returning to school in a registered nurse $(\mathrm{RN})$ or bachelor of science in nursing degree (BSN) program. Use email as a direct mail mechanism, sending messages periodically at established times so that everyone begins to enthusiastically anticipate its receipt. Write teaser book reviews with unconventional, quirky subject lines to draw interest in opening your email, and close your message body with a prelude to a mysterious end to be read only in a following email. If you send a print mail piece, think about novel designs, such as a booklet or die-cut shape. In direct marketing, including an active pull mechanism, where recipients have to perform a task - such as send an email, place a sticker on a response card, or call to discover the complete message-builds intrigue, but more importantly, establishes commitment.

Produce a live skit or short advertisement and post a video of it on your intranet or library web pages. Integrate it with other promotional message mechanisms such as direct marketing, and mass email it within your organization. Think about current trends and pop culture to create novel spoofs. With a written marketing plan in place, knowing where to head and moving forward becomes a matter of action.

In this current environment of change-where many health sciences libraries are being downsized, restructured, or permanently closed-it is in your library's best interest to rise onto the radar and maintain visibility. It has been noted that "to manage changes effectively involves the ability to create a new synthesis of people, resources, ideas, opportunities, and demands" [3]. Many librarians mention avoidance as a key strategy in hopes of not being scrutinized. Too often, a librarian will be heard saying, "I will hold tight with the budget, staff and services that I have so as not to draw attention." It may be detrimental not to market, since it is very unlikely for a nondescript, covert library to receive positive appreciation or recognition. A proactive approach is much more beneficial. More than forty years ago, the astute William B. Condon, trustee of the Denver Medical Society, wrote, "frankly, a trustee wishes to be constantly, but gently, astutely, and diplomatically, nudged to keep his library functioning!" [1]. Librarians can benefit by following business practices to continually emphasize marketing promotion, and in essence, bring focus upon their libraries through strategic market planning.

\section{REFERENCES}

1. Condon WB. A medical society trustee looks at his library. Bull Med Libr Assoc. 1967 Jan;55(1):52-4.

2. Case DO, Andrews JE, Johnson JD, Allard SL. Avoiding versus seeking: the relationship of information seeking to avoidance, blunting, coping, dissonance, and related concepts. J Med Libr Assoc. 2005 Jul;93(3):353-62. 3. Barnes PC. Managing change. BMJ. 1995 Mar 4; 310(6979):590-2.

\section{AUTHOR'S AFFILIATION}

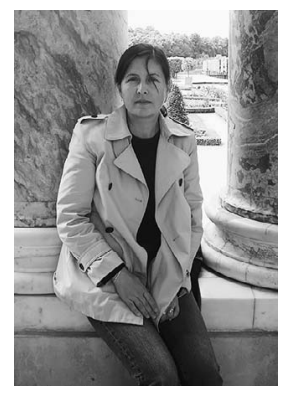

Sue Espe, BBA, MLIS, AHIP, suefue.espe@bannerhealth.com, Health Science Librarian, Banner Health-University Medical Center, 1111 East McDowell Road, Phoenix, AZ 85006

Received December 2015; accepted February 2016

\title{
An elemental strategy
}

\section{Nancy K. Roderer, MLS, FACMI, AHIP, FMLA}

See end of article for author's affiliation.

As medical libraries evolve and grow in the digital era, much has been much written about different aspects of the changes that have occurred. Less
DOI: http://dx.doi.org/10.3163/1536-5050.104.3.013

literature traces interrelated developments in a specific library over an extended period of time. To address this lack, the management team of the Welch 
Medical Library at Johns Hopkins University wrote a chapter [1] for the Association of College and Research Libraries (ACRL) book, Difficult Decisions: Closing and Merging Academic Libraries [2], which described the evolution of the Welch library between 2000 and 2013, a period in which a long-range strategic plan was developed and implemented. The ACRL book chapter reviews the status of library services, collections, and facilities as of 2013; discusses staffing and financial issues; and describes the library plan as of 2013, as this excerpt shows:

On the surface, the saga of the Welch Medical Library is about a library building and a collection of books within it, but there is also a story about the dramatic evolution of library services and expectations in the context of changing technology. While these threads are tightly interwoven, and both are important, it seems likely that it is the latter that will have the most lasting impact on users of the library and the work that they do.

Our story begins with the opening of the Welch library building in 1929. The library was to function as a central library for the medical campus of Johns Hopkins, and the building also accommodated the Institute of the History of Medicine (IHOM) and its collection. As the campus grew, so did the library's staff, collection, services, and locations, but the building continued to serve its central function reasonably well for over 50 years. Of particular importance to the Hopkins community was the grand reading room, which houses the Sergeant painting of the Four Doctors which commemorates the founding of the Johns Hopkins hospital and medical school in 1889 and 1893 respectively.

The Welch library staff aggressively pursued the application of evolving technology to library services and collections, and, as elsewhere, library materials and services increasingly began to be used from outside the library building. By 2000, both the problems with the existing building and the direction of electronic services seemed to call for a new vision of library services and a relook at the building. Through consultation with library users and with the assistance of an architectural team, it was envisioned that by 2013 library services and collections would be predominantly electronic, provided to users "wherever they are."
The period of 2000-2012 saw rapid increases in electronic collections and evolution of embedded services to library users, both guided by a series of action plans. All physical branches of the central library were closed, and plans were developed to reuse the central library portion of the Welch library building in support of graduate student education. The library staff moved out of the Welch building, maintaining a small service desk on site.

Progress since 2013 is slow but remains true to the concept of serving the users wherever they are. A renovation of the Welch library building, focusing on the main reading rooms and building infrastructure issues, was completed in early 2014. Since then, the building has drawn increased use and seen many events hosted in the grand reading rooms. The services provided to users wherever they are continue to grow. The informationists and other staff are more deeply engaged than ever with faculty, researchers, clinicians, and students, and library services are more integrated into the work of users. These activities have been and will be documented in additional publications and presentations.

\section{REFERENCES}

1. Roderer N, Anton B, Bryant W, Gresehover R, Seal S, Twose C, Woodson $S$. The very model of a modern major library. In: Holder S, Lannon AB, eds. Difficult decisions: closing and merging academic libraries. Chicago, IL: Association of College and Research Libraries; 2015. Chapter 5.

2. Holder S, Lannon AB, eds. Difficult decisions: closing and merging academic libraries. Chicago, IL: Association of College and Research Libraries; 2015.

\section{AUTHOR'S AFFILIATION}

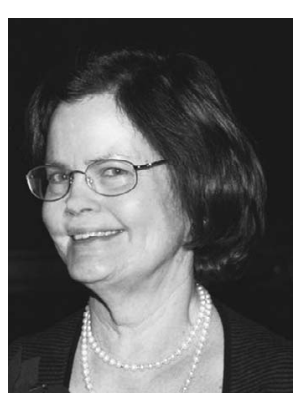

Nancy K. Roderer, MLS, FACMI, AHIP, FMLA, nroderer@jhmi.edu, Professor Emerita, Division of Health Sciences Informatics, School of Medicine, Johns Hopkins University, Baltimore, MD 